\title{
Mining Region Economy Servization (on example of Kemerovo Region-Kuzbass)
}

\author{
Olga Esina ${ }^{1}$, Natalia Tereshchenko ${ }^{1, *}$, and Tatiana Pakshina ${ }^{2}$ \\ ${ }^{1}$ Siberian Federal University, 660075 Lida Prushinskaya St. 2, Krasnoyarsk, Russia \\ ${ }^{2}$ Vitebsk State Technological University, 210038, 72 Moskovsky av., Vitebsk, Belarus
}

\begin{abstract}
The social-and-economic development of the regions is largely determined by the state and specific features of the service industries' development. The high-quality level of transport, housebuilding, communications, education and science, health care and other sectors of this industry creates the preconditions for sustainable growth of all spheres of the national economy. The article defines the development dynamics in the service sector in Kuzbass, its significance in the formation of the gross regional product, analyzes the average per capita volumes and the structure of service sector revenue in the Kemerovo region in comparison with the indicators in the Russian Federation and Siberian Federal District. Based on the research carried out, the specific features and trends in the development of the service sector in the region have been identified.
\end{abstract}

\section{Introduction}

The formation of the regional economy structure occurs under the influence of a number of objective factors, such as historical, climatic, infrastructural, technological conditions of development. However, regardless of the cumulative impact of many constituent indicators, one of the most dynamically developing sectors of economy is the service sector.

In modern conditions of economic development and globalization processes, the service sector significantly affects both the volume of economy and the structure of the gross domestic product. According to the information resource CIAWordFactbook [1], the share of the service sector in the formation of the gross product in 19 countries with the largest GDP, accounts for from $45.4 \%$ in India to $80.2 \%$ in the UK. Russia ranks the 6th by this indicator and over the past decade the share of the service sector in the country's GDP ranges from $70.66 \%$ in 2014 to $62 \%$ in 2017 [2]. At the same time, all other values for this indicator arranged by the years are within the specified interval.

In the context of the federal districts of the Russian Federation, the share of the service sector in the gross regional product ranges from $42 \%$ in Urals Federal District to $75 \%$ in Central Federal District (Fig. 1).

\footnotetext{
*Corresponding author: tereshchenko.65@mail.ru
} 


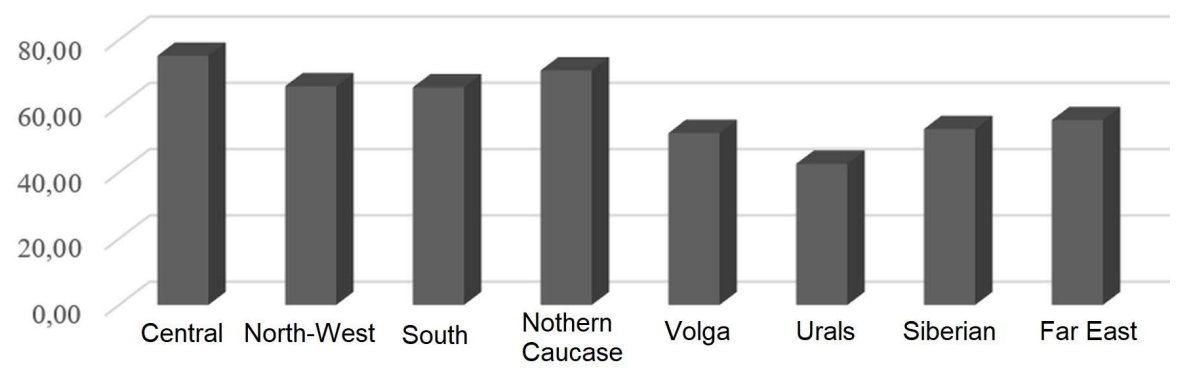

Fig. 1. The share of the service sector by Federal Districts of the Russian Federation in 2019, \%.

Thus, we can say that the structural composition of the regional economy has a significant impact on its social-and-economic development, while the service sector, along with the extractive industries and the production sector, plays an important role in this process.

\section{Materials and Methods}

The issues of research and modeling of the service sector development are described in the works of both foreign and domestic researchers.

A number of scientists (Kitova O.V., Savinova V.M., Dyakonova L.P., Bruskin S.N., Beshmelnitskiy A.A., Danko T.P., Sekerin V.D.) [3] offer methodological approaches to the study of the service sector through the creation of situational centers. They focus on assessing social-and-economic indicators at different levels, planning and factor analysis in real time and forecasting the development of the service sector using a variety of qualitative and quantitative methods.

Many foreign and domestic scientists (Razumova, E., Ilienko, O., [4] Dalevska N., Khobta V., Kwilinski A., Kravchenko S. [5], Dmitrieva M., Strekaleva T., Suslov D., Tereshchenko N. [6], Demchenko, S.K., Zlotnikov M.S., Melnikova T.A., Demchenko O.S. $[7,8]$ ) propose a methodological tool in the field of analysis and economic modeling of the service sector as a whole and for individual constituent industries.

Generalization and critical analysis of the works of domestic and foreign authors allows determining a number of basic characteristics of the service sector as a central sector of the economy at all levels.

Firstly, the service sector is an indicator of the social-and-economic development of the region. The civilizational approach to the study of the society development (theories of D. Bell, E. Tafler, A. Lesch) puts forward the state of the service sector as the main characteristics of industrial and post-industrial society. As this sector of economy determines the transformed resources in the form of knowledge, information, storage systems and data processing and key intelligent technologies. Thus, a high or constantly increasing level of development of the service sector testifies to the successful social and economic development of the regions.

Secondly, the service sector acts as the main factor in the development of production. By improving the occupancy and content of service industries, the formation and interaction of the main classical factors of production takes place, since it is with the use of intelligent technologies that individual and collective skills, production and exchange technologies are developed, the significance of the results achieved increases.

Thirdly, the service sector can be viewed as an indicator of ensuring the quality of life of the population. A number of basic characteristics identified by UNESCO as part of assessing the life quality, such as safety, health, education, rational nutrition, are formed with the direct participation of certain service industries. Therefore, the higher the level of development of 
a given sector of economy, the more qualitative characteristics are determined by the standard of living of the population.

As already noted, the development of the service sector is influenced by many factors that determine its state in various territories.

The object of our research is Kuzbass. The Kemerovo region is one of the technologically advanced mining regions of the Russian Federation, in connection with which the service sector in Kuzbass has a certain specificity, which is advisable to consider through a number of indicators:

- the share of the service sector in the formation of the gross regional product;

- the dynamics of the revenues' volume in service industries for a number of years;

- the average per capita revenue in service industries per 1000 inhabitants;

- the structural changes in main types of services provided to the population.

The Russian practice of statistical research reflects the results of the activities of economic sectors in accordance with the Russian National Classifier of Economic Activities Types, which introduced a number of changes that do not imply a clear separation of three main sectors of economy: extractive industries and agriculture, manufacturing and services. In this regard, the structuring of statistical data provided by the Federal State Statistics Service [2] makes it possible to determine the share of participation of the above groups of industries in the formation of the gross domestic product and gross regional products of the objects of research.

\section{Results and Discussion}

A comparative characteristic of the service sector importance in the economy of the Russian Federation, Siberian Federal District and the Kemerovo region is shown in Figure 2.

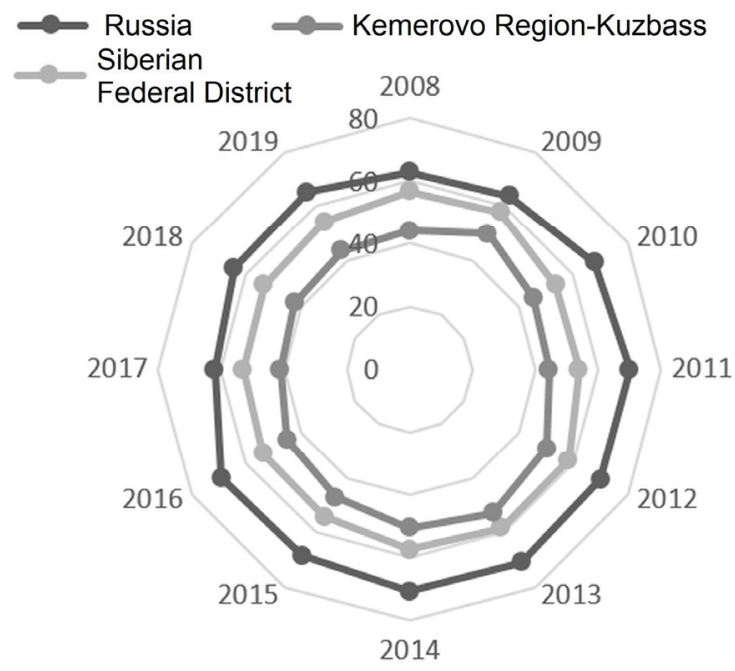

Fig. 2. Dynamics of the share of the service sector in the GDP of the Russian Federation and the GRP of Siberian Federal District and the Kemerovo region in 2008 - 2019, \%.

The data analysis shows that in the Russian Federation in the period from 2008 to 2019 the share of service industries accounted for from $71.01 \%$ in 2013 to $62 \%$ in 2017 . In recent years, there has been a slowdown in the rate of increase in the volume of services, and, accordingly, its share in the gross domestic product. A similar situation is observed in the 
economy of Siberian Federal District. Here the interval of participation of the service sector in the formation of the gross regional product ranges from $58.4 \%$ in 2013 to $53.1 \%$ in 2017 . The share of the service sector in the formation of the gross regional product in the Kemerovo region, ranges from $50.7 \%$ in 2014 to $41.2 \%$ in 2017 and is slightly lower than in the Russian Federation and Siberian Federal District.

Thus, it can be noted that the importance of the service sector in the economy of Kuzbass is not so significant, although it accounts for more than a third of the enterprises revenues in the region, which is explained by the focus of the region on the mining and manufacturing sectors.

Comparative characteristics of the dynamics of the change chain rates in the revenue of the subjects in the service sector, presented in Figure 3, shows that in all three analyzed regions there is a positive change in this indicator, with the exception of 2017, when there was a decrease in Siberian Federal District (86.75\%) and in the Kemerovo region (99.44\%).

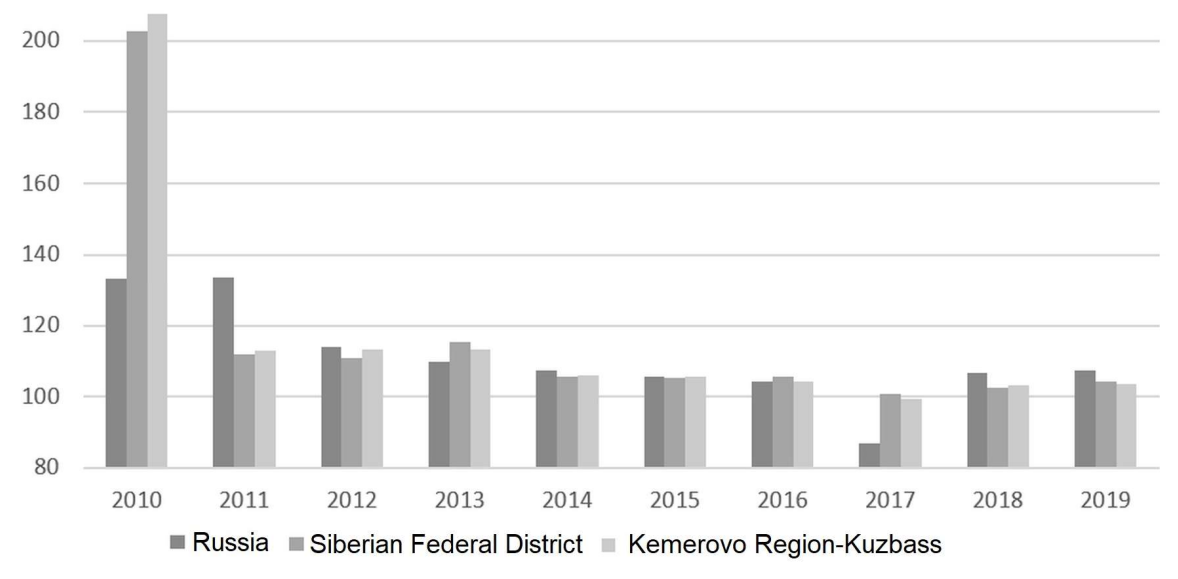

Fig. 3. Dynamics of revenue in service industries in the Russian Federation, Siberian Federal District and the Kemerovo region in 2010-2019, \%.

At the same time, it should be noted that the largest increase in the revenue of service sector entities was observed in 2010 for all research objects. The rate of increase in the volume of service industries in the Kemerovo Region is comparable to the average Russian and the indicators of Siberian Federal District, but we can note some lag in the last 4 years. Thus, we can note the positive dynamics of the development of the service industries in Kuzbass, which, however, is taking place at a slower pace than in the Russian Federation and Siberian Federal District.

One of the characteristics of the service sector development is the average per capita revenue of industries per 1000 residents, which makes it possible to form an estimate of the consumption of services both in dynamics and in comparison by regions.

Table 1. GDP of the Russian Federation and GRP of Siberian Federal District and the Kemerovo region from the service industries per 1000 residents of the region, million rubles. (Compiled according to [2]).

\begin{tabular}{|c|c|c|c|c|c|c|}
\hline & $\mathbf{2 0 0 9}$ & $\mathbf{2 0 1 1}$ & $\mathbf{2 0 1 3}$ & $\mathbf{2 0 1 5}$ & $\mathbf{2 0 1 7}$ & $\mathbf{2 0 1 9}$ \\
\hline $\begin{array}{c}\text { The Russian } \\
\text { Federation }\end{array}$ & 142.9 & 254.56 & 316.85 & 351.29 & 323.9 & 326.6 \\
\hline
\end{tabular}




\begin{tabular}{|c|c|c|c|c|c|c|}
\hline $\begin{array}{l}\text { Siberian Federal } \\
\text { District }\end{array}$ & 100.5 & 134.5 & 167.8 & 191.8 & 213.1 & 218.3 \\
\hline $\begin{array}{l}\text { The Kemerovo } \\
\text { region }\end{array}$ & 90.4 & 120.3 & 128.9 & 146.1 & 160.9 & 166.4 \\
\hline
\end{tabular}

Analysis of the data summarized in Table 1 makes it possible to reveal the positive dynamics of the development of this indicator for almost all objects of study and in all periods, however, its cost characteristic is ambiguous. It should be noted that in the Kemerovo region in 2019 the volume of services per 1000 residents amounted to 0.51 points from the national average and 0.76 points from the indicator of Siberian Federal District. Thus, every resident of Kuzbass was provided services for about 13 thousand rubles per month (including utilities, medical, educational, communication services, transport, etc.), despite the fact that the national average of this figure was about 27 thousand rubles, and in Siberian Federal District it was about 18 thousand rubles.

Thus, we can conclude that the development of the service sector in the region lags behind the average Russian and subject indicators and creates an opportunity for setting up and developing of business in the relevant sectors of economy.

As it was noted earlier, there is no special form of accounting for services, including by type of activity in the State Statistics. Certain information is presented in the information and analytical system "Statistics" [9] and statistical collections of the Higher School of Economics [10]. Generalization of the data from the above sources allows making a judgment about the consumption structure of services by the population of the Kemerovo region in Table 2 .

Table 2. Dynamics of the structure of revenue from the provision of services in 2000-2019 in the Kemerovo region (compiled according to $[9,10])$.

\begin{tabular}{|c|c|c|c|c|c|c|}
\hline & & & & \multicolumn{3}{|c|}{ Deviations } \\
\cline { 5 - 7 } Services & $\mathbf{2 0 0 0}$ & $\mathbf{2 0 1 0}$ & $\mathbf{2 0 1 9}$ & $\begin{array}{c}\mathbf{2 0 1 0} \\
\text { from } \\
\mathbf{2 0 0 0}\end{array}$ & $\begin{array}{c}\mathbf{2 0 1 9} \\
\text { from } \\
\mathbf{2 0 1 0}\end{array}$ & $\begin{array}{c}\mathbf{2 0 1 9} \\
\text { from } \\
\mathbf{2 0 0 0}\end{array}$ \\
\hline Domestic services & 19.36 & 8.60 & 11.34 & -10.76 & 2.74 & -8.02 \\
\hline Veterinary services & 0.17 & 0.13 & 0.14 & -0.04 & 0.01 & -0.03 \\
\hline Housing services & 6.92 & 8.24 & 9.46 & 1.32 & 1.22 & 2.54 \\
\hline Utilities services & 14.90 & 23.38 & 23.58 & 8.48 & 0.20 & 8.68 \\
\hline Medical services & 4.38 & 6.51 & 7.12 & 2.13 & 0.61 & 2.74 \\
\hline Legal services & 1.09 & 1.84 & 1.09 & 0.75 & -0.75 & - \\
\hline Sanitary and wellness & 2.88 & 1.90 & 1.40 & -0.98 & -0.05 & -1.48 \\
\hline Educational services & 5.62 & 6.78 & 7.12 & 1.16 & 0.34 & 1.50 \\
\hline Transport services & 28.10 & 13.20 & 12.85 & -14.90 & -0.35 & -15.25 \\
\hline Tourist and excursion & 0.38 & 3.93 & 3.97 & 3.55 & 0.04 & 3.59 \\
\hline
\end{tabular}




\begin{tabular}{|c|c|c|c|c|c|c|}
\hline Hotels, motels & - & 1.41 & 1.10 & 1.41 & -0.31 & 1.10 \\
\hline Communications & 8.78 & 20.30 & 16.02 & 11.52 & -4.25 & 7.24 \\
\hline Cultural institutions & 1.24 & 1.43 & 1.57 & 0.19 & 0.14 & 0.33 \\
\hline $\begin{array}{c}\text { Physical culture and } \\
\text { sports }\end{array}$ & 0.26 & 0.76 & 1.10 & 0.50 & 0.34 & 0.84 \\
\hline Other services & 5.92 & 1.58 & 2.15 & -4.34 & 0.57 & -3.77 \\
\hline Total & 100.0 & 100.0 & 100.0 & - & - & - \\
\hline
\end{tabular}

Analysis of the data in the table allows determining that over the past twenty years, the consumption structure of services by the population of Kuzbass has changed significantly. If in 2000 the main share was accounted for transport (28.1\%), domestic $(19.36 \%)$ and utilities $(14.9 \%)$ services, then in 2019 , the share of communication $(16.02 \%)$ and utilities $(23.56 \%)$ services is significantly increasing, at the same time, the share of transport services remains significant $(12.85 \%)$ too. Veterinary services $(0.14 \%)$, legal services $(1.09 \%)$, services of hotels and motels, and services of physical culture and sports $(1.10 \%)$ have insignificant shares in the structure of revenues from the provision of services.

Thus, a thesis about the possibility of entrepreneurship development in these service sectors arises.

\section{Conclusion}

The service sector is one of the most important sectors of economy, determining many aspects of the national economy development. The studies carried out made it possible to determine a number of specific features of the service sector development on the territory of the Kemerovo region - Kuzbass, which may be summarized in the following provisions:

- There is lower importance of the service sector in the formation of the gross regional product than in the Russian Federation and Siberian Federal District.

- There are slower rates of development of this sector of economy in comparison with the average Russian and subject indicators.

- There is a significant lag in the volume of services per 1000 residents from the average in the country and Siberian Federal District.

- There is poor development of certain branches of the service sector related to the development of health, legal support, culture, recreation.

All of the above allows making the conclusion that business development in this territory has great opportunities in the service sector.

It should be noted that the "Strategy for the social-and-economic development of the Kemerovo region - Kuzbass for the period up to 2035" [11] pays considerable attention to the development of the service industries. The main principles are high quality and reliable provision of a new standard of living and meeting the needs of residents. In this regard, four main development priorities have been formed, ensuring professional excellence, high quality of life, and a green economy for residents. The presented provisions will undoubtedly contribute to the development of the service sector in Kuzbass. 


\section{References}

1. C.I.A. theWorldFactbook. URL: https://www.cia.gov/library/publications/the-worldfactbook/.

2. Rosstat, Official Website. URL: www.gks.ru

3. O. Kitova, V. Savinova, L. Dyakonova, S. Bruskin, European Research Studies Journal, 20(4), 275-283 (2017)

4. E. Razumova, O. Ilienko, V. Ihnatiuk, Baltic journal of economic studies, 4(2), 191-197 (2018)

5. N. Dalevska, V. Khobta, A. Kwilinski, S. Kravchenko, Entrepreneurship and Sustainability Issues, 6(4), 1839-1860 (2019)

6. M. Dmitrieva, T. Strekaleva, D. Suslov, N. Tereshchenko, Proceedings The 32nd IBIMA conference (Seville, Spain, 2018)

7. S.K. Demchenko, M.S. Zlotnikov, T.A. Melnikova, O.S. Demchenko, International Journal of Civil Engineering and Technology, 10(2), 1877-1884 (2019)

8. S. Zhironkin, S. Demchenko, G. Kayachev, E. Taran, O. Zhironkina, E3S Web Conf. 105, 03008 (2019)

9. Information and analytical system "Statistics". URL: www.ias-stat.ru/

10. HSE, Statistical collections. URL: https://www.hse.ru/primarydata/

11. Strategy of socio-economic development of the Kemerovo region-Kuzbass for the period up to 2035 (AKO, Kemerovo, 2019) 